MedieKultur | Journal of media and communication research | ISSN 1901-9726

Editorial

\title{
Field theory approaches to new media practices: An introduction and some theoretical considerations
}

\section{Ida Willig, Karen Waltorp, and Jannie Møller Hartley}

MedieKultur 2015, 58, 1-12

\begin{abstract}
Published by SMID | Society of Media researchers In Denmark | www.smid.dk The online version of this text can be found open access at www.mediekultur.dk
\end{abstract}

\section{Introduction}

The field theory of French sociologist Pierre Bourdieu has proven useful across a range of research areas and constitutes a promising theoretical framework for analyzing the media (Benson 1998; Benson \& Neveu 2005; Couldry, 2005; Marlière, 1998; Willig, 2012, Willig forthcoming).

This special issue of MedieKultur specifically addresses new media practices and asks how field theory approaches can help us understand how culture is (prod)used via various digital platforms. In this article introducing the theme of the special issue, we argue that studies of new media practices could benefit particularly from Pierre Bourdieu's research on cultural production. We introduce some of the literature that concerns digital media use and has been significant for field theory's development in this context. We then present the four thematic articles in this issue and the articles outside the theme, which include two translations of classic texts within communications and media research. This introductory article concludes by encouraging media scholars to embark on additional studies within a field theory framework: This framework's comprehensive theoretical basis and ideal of a reflexive sociology are capable of prompting important questions without necessarily claiming to offer a complete and self-sufficient sociology of media, including new media. 


\section{Field theory and media studies}

In his wide-ranging research, Bourdieu has touched only briefly upon the importance of media for social practice, for instance in his book on Photography: A Middle-Brow Art (Bourdieu et al., 1990/1965) and his polemical and much-criticized book On Television (1998), which represents his closest attempt to analyze the influence of a specific media platform. On Television (originally published in 1996 as Sur la television) was written more as a contribution to a social debate on the influence of television on current cultural production than as a treatise on the sociology of journalism. We will nevertheless argue that it is worthwhile for media scholars to read and use Bourdieu when considering new media practices because his comprehensive social theory can promote a better understanding of social practices and address questions of power and cultural production. His theoretical framework assists in relational thinking, moving from micro to macro, and transcending well-known binaries such as structure versus agency. We suggest - as is backed up by the articles in this special issue - that inspiration can be retrieved not so much from Bourdieu's scanty writings on media as from his richer research on cultural production.

Exploring Bourdieu's books on culture, education, and intellectuals thus has more to offer in terms of developing an analytical framework that can be adopted for analyzing new media practices. Readings that can inspire media scholars include his classics on the practice of photography (Bourdieu, 1990 - English 1965), the uses of museums (Bourdieu, 1969), the French system of education (Bourdieu, 1984; Bourdieu and Passeron, 1964, 1970), the sociology of language (Bourdieu, 1982), his study of Heidegger's philosophy (Bourdieu 1975, 1988), and also the Rapport pedagogique et communication (Bourdieu et al., 1968). Many of the studies analyzing uses of digital technologies have, as we shall see below, been inspired by the Bourdieu classic Distinction (1979/1984).

Over the years, it has thus been necessary for scholars working with media practices to develop field theory into a more comprehensive and nuanced media theory, one that permits analysis of media reception, media content, and media production. We can see this process at work in the development of the concept of a media meta-capital (Couldry, 2003) and in studies analyzing the Journalistic Field (see Benson and Neveu, 2005; Schultz, 2007; Wiik, 2010; Hovden, 2008). Whereas Bourdieu is gaining foothold within journalism research, perhaps because the French sociologist himself has undertaken some preliminary work on the field of journalism, he is less widely employed within media and communication studies in general. Only a few studies have explored the usefulness of field theory within a new media context, with on example being Nancy Baym's ethnographic studies of online communities focused on examining their social organization and struggles over meaning (Baym, 1999). Ethnographic methods have also been used in a study of Danish online journalists, which discusses the practice of routinizing breaking news (Møller Hartley, 2011), and in a study of a new audience-driven and source-detached role perception (Møller Hartley, 2013). These types of studies share a focus on media production or classic 
correspondence analysis of a field, such as the field of journalism in specific countries (see for example Wiik, 2010; Hovden, 2008). New media reception and media audiences have received less attention.

\section{Fields as structuring new media practices}

There is thus a need to further develop the field theory framework to enhance our empirical understanding of new media and new media practices. This issue of MedieKultur presents four thematic articles that aim to do exactly that. It is likely, however, that Bourdieu would not consider new media a decisive break from the hitherto-known forms of communication as he regards the institutionalization of fields in line with what is termed 'path dependency' within new institutionalism; that is, previous historical battles have a certain limiting effect on the future (Benson, 2005). As Bengtsson (this issue) shows, there seem to be strong links between cultural capital, cultural consumption, and new media usage.

Bourdieu's theories follow Max Weber and Emile Durkheim and view modernity as a process of differentiation into semi-autonomous and increasingly specialized spheres of action - 'fields'. These fields are structured systems of social relations. They are the mesolevel environments, between the organizational and societal level, that structure social action. This is why Bourdieu is useful for transcending structure versus agency binaries. In principle, there are as many fields as there are specialized realms of human activity: literary, artistic, scientific, religious, economic, journalistic, etc. We would, however, question whether one can speak of a media field: Identifying a field is more a question of practical investigation than of theoretical definition. 'Field' should not be an omnibus concept but instead an open question for empirical analysis. We could even claim that it is not particularly useful to explore very small social worlds or worlds with very low levels of institutionalization or weak concentrations of resources and powers. In this case, it might be more useful to focus on some of the other useful concepts in Bourdieu's comprehensive work, such as capital, habitus, or illusio. Bourdieu writes in his Invitation to Reflexive Sociology that a field exists when it triggers "field effects" (Bourdieu in Neveu, 2007). A social space comes to work as a field when the institutions and characters that enter it are a part of and feel its stakes, values, and debates, when one cannot succeed in it without a minimum level of practical or reflexive knowledge of its internal rules and logics. The job for the researcher is thus to analyze the stakes and the 'becoming' part of a field: What beliefs do a certain group of agents, for example, hold concerning good taste or the rules of the game? How do the agents struggle to obtain the resources and their forms of capital?

Despite this, field theory, according to Benson and Nevue (2005: 8), provides a good starting point for investigating "the complex relationship between new and old media." In this issue of MedieKultur, we consider how field theory can provide analytical tools for understanding the media and media practices and the ways in which field theory has been 
- or could potentially be - developed in accordance with the new media realities. In addition, this issue explores the relationship between 'new' and 'old' media.

\section{Field approaches to studies of new media practices}

In the following, we focus on studies that deal with digital media practices from a field perspective; a review of studies on the uses of all kinds of media would prove too broad in this context. In reviewing the studies, it nevertheless becomes clear that the use of new media is intertwined with the use of older media platforms, and we see that digital media use tends to complement - rather than replace - existing forms of media use. We provide some examples of studies that have taken a Bourdieusian approach to the use of digital media, including the four articles in our thematic issue.

As Bengtson (this issue) points out, there are two primary strands in the field of Bourdieusian studies of Internet use and online practices: firstly, studies of how socio-cultural and economic heritage are linked to variations in online habits and Internet use, approached quantitatively as well as qualitatively, and secondly, studies of how users of different socioeconomic status use different content and benefit from it in different ways. The first strand of studies is inspired by Bourdieu's work in the classic text Distinction from 1979. An example of this is Eszter Hargittai's (2010) quantitative study that demonstrates socio-economic status as an important predictor of how people incorporate the Internet into their daily lives. These conclusions are also supported by studies by Van Dijk and Hacker (2003) and Petrov and von Feilitzen (2005). Capital-enhancing activities include searching for information and acquiring knowledge and skills that are useful in other areas of society as well, whilst less capital-strong users do not benefit from their Internet use in the same manner (Hargittai and Zillien, 2009).

Howard, Rainie, and Jones (2001) are among the first to investigate types of activities by user background, finding considerable differences according to socio-economic status. Analyzing data from a national sample of Internet users, these authors find that those with a university degree or higher were more likely to seek health information, engage in financial transactions, research and look for job information, and get news than those with lower levels of education. Level of education was negatively correlated with online engagement in such activities as browsing just for fun, playing a game, or gambling online (Howard, Rainie, and Jones, 2001). From studies such as this, we know how people use digital technologies and how this is linked to their backgrounds in different ways, but there remains much work to be done to relate such findings to the logics of a field, without assuming that the digital is a field.

DiMaggio et al. (2004) refer to the distinction between the former and latter set of activity types presented by Howard et al. as 'capital-enhancing' versus recreational, suggesting that the former are types of online actions from which people may benefit whereas the latter likely have fewer pay-offs related to one's social status. Hargittai and Hinnant 
(2008) use this classification to examine how a national sample of American young adults aged 18-26 incorporated the Internet into their daily lives. The results from that paper are consistent with those of Howard, Rainie, and Jones (2001): Education is positively associated with capital-enhancing online activities.

These findings suggest that Internet access may not, in and of itself, level the playing field when it comes to the potential payoffs of being online. Instead, those from more privileged backgrounds may reap more of its benefits if they are more likely to use it in potentially beneficial ways (Hargittai, 2008).

How can we take a theory of what was highbrow and lowbrow in France in the 1970s and transfer it to any European or Western context? We must be cautious and reframe field theory in light of new empirical realities. And we must constantly ask questions with regard to the specific field in question: What are the stakes? What is valued? How is it valued differently by different people? This calls for additional qualitative studies developing the concept of capital and inquiring into the definitions of specific fields.

In their qualitative study, North et al. (2008) find a strong link between technology use and the social class of young Internet users: Informed by Bourdieu's notions of habitus and taste as well as Raymond Williams' notion of cultural form, North et al. suggest a strong link between technology use and class difference. They argue that markers of class such as parents' level of education and occupation influence the habitus of young people, which in turn influences their digital tastes. The case studies set out to explore young people's digital communication practices at home and in school. The findings show the importance of habitus in young people's engagement with and interest in digital technologies. They found that new experiences, objects, actions, and accomplishments using digital technologies were accepted as valuable or rejected as not valuable depending on how well they fit with pre-existing thoughts and processes incorporated into the young people's habitus. The article concludes that the link between cultural capital, habitus, and cultural form produces a socially entrenched digital inequality rather than an economically entrenched digital divide.

Robinson (2009) has illustrated the relationship between access and non-access to digital media, use habits, and the ways in which users can benefit from these habits. These questions have also been understood through a focus on family relationships and the importance of habitus in cultural reproduction (Hollingworth et al. 2011; see also Schofield-Clark, 2013). Meyen et al. (2010) have studied the kinds of capital that are acquired online and the factors that influence use patterns. These represent small but important steps towards understanding media practices, in this case the use of digital media, and redeveloping the concept of capital accordingly.

In a Swedish setting, Danielsson (2014) explores how social class matters in young men's everyday relationships to digital media and presents an empirically grounded critique of popular ideas concerning young people as a 'digital generation', about the internet as a socially transformative force, and about class as an increasingly redundant category. The 
empirical material consists of qualitative interviews with 34 young men (16-19 years old) from various class backgrounds, upper-secondary schools, and study programmes. Drawing upon the conceptual tools of Bourdieu, the analysis shows that class, through the workings of habitus, structures the young men's relationships to school and future aspirations. This also engenders class-distinctive ways of conceiving leisure and digital media use. Through their class habitus and taste, the young men tend to orient themselves and navigate in different ways in what they perceive to be a space of digital goods and practices, endowed with different symbolic value in school and society. The "cultural capital rich" are drawn towards practices capable of yielding symbolic profit in the field of education and beyond, whereas the other classes gravitate towards the "illegitimate" digital culture but deal with it in different ways.

These findings indicate that there are social and cultural continuities at play within recent technological changes. One of the most important insights from this is the importance of relating Internet use to the wider spectra of cultural practices. Bourdieu's cultural studies and sociological approach are a good place to start precisely for this reason. The four thematic articles in this issue of MedieKultur can be characterized as studies that analyze media use. However, they focus on different concepts within field theory and apply different methodological approaches. They also differ in relation to their focus on new media in particular or on the relationship between new and old media.

\section{The four articles in this special issue}

In this special issue, Stina Bengtsson takes students' cultural preferences in general and highbrow cultural preferences in particular as a vantage point for analyzing acts of distinction in everyday life online. She does so on the basis of a survey study of university students from Södertörn University, Sweden. The article pays specific attention to the webpages the students mention and provides detailed information on these areas, and the mechanisms of difference of digital media use is revealed through an analysis of the differences between students who can be considered part of the same field. The analysis reveals the importance of micro-level analyses to understand digital media use from a cultural perspective. Although the information on web content provided by this study is detailed, digital media platforms (such as Facebook), can be used in a great variety of ways, and they provide users with diverse kinds of content, depending on the character of their own personal networks, which calls for further qualitative studies of the same group.

Claus Toft-Nielsen and Stinne Gunder Strøm Krogager investigate digital game play (gaming) as a specific media field in which gaming capital (Consalvo, 2007) in particular functions as a theoretical lens. Empirical data from focus groups as well as participant observation shed light on the specific practices that constitute and are constituted in and around gaming. The authors do this by combining field theory with practice theory, in fact building upon Bourdieu's early work, which inspired the so-called second generation of 
practice theorists (Bräuchler and Postill, 2010; Reckwitz, 2002; Schatzki, 2008; Warde, 2005). This practice-based approach raises broad questions about the sorts of things people regularly do with media amid the proliferating complexity of digital media and everyday life, and it enables the researchers to adopt a micro-approach to the analysis of specific media practices. The practice-based approach in the article highlights the interconnectivity of the use of technologies involved in media consumption as it moves away from understanding media consumption as fixed types and reframes consumption as continuous, relational accomplishments in multiple, intersecting everyday life practices. The authors argue that the practice theory approach adds detail and nuance to the empirical material. In the article, we are shown how changes in specific kinds of media consumption have allowed for new types of socialities, new possibilities of doing 'togetherness', and new forms of practices that grow out of the activities and elements of older, previous practices.

The article 'Keeping Cool, Staying Virtuous' builds upon long-term, anthropological fieldwork among young Muslim women in a social housing area in Copenhagen. In the article, Karen Waltorp explores how morality, modesty, and gender and generational relationships are reconfigured in the ways in which young women use smartphones and social media to navigate their everyday lives. The focus is on love and marriage, on the imperatives of keeping cool among peers, and on simultaneously keeping the family's honour intact through the display of virtuous behaviour. Building upon Bourdieu's writings on split habitus, the article introduces the term composite habitus, as it underscores the aspect of a habitus that is split between sometimes contradictory composite parts. The composite habitus of the young women is, however, more than a hysteresis effect in which disposition and field are in mismatch and the habitus misfires; it also opens up a range of possible strategies. The analysis presents examples of how intimate and secret uses of smartphones have played out and shows how social media has permitted multiple versions of self and the management of public and secret relationships locally as well as across great distances.

André Jansson's article in this issue also takes as its theme regulation of membership of a field and communication across distances via social media. In his primarily theoretical article, Jansson develops a Bourdieusian approach to mediatization and argues that Bourdieu's theories of doxa and fields can make valuable contributions to a critical perspective on mediatization, one that moves beyond the divides between institutionalist, social-constructivist, and materialist understandings. Mediatization is here seen as the historically growing dependence on media technologies and institutions within diverse social fields and settings. In order to establish the link between mediatization and Bourdieu's theory, the article introduces the concept of communicational doxa, which refers to the taken-forgranted communicative conventions and demands that regulate criteria for membership of a certain field. Jansson's article also shows how communicational doxa can be applied as an analytical concept. Findings from qualitative fieldwork carried out among highly mobile and skilled professionals within the field of UN organizations in Geneva show how the 
autonomy of social agents is negotiated in relation to an increasingly mediatized communicational doxa.

Jansson illustrates how the field of UN organizations has exposed a social phenomenon that can be described as "osmotic pressure". He argues that the ubiquitous nature of new media makes the UN workers highly absorbable by communicational doxa, while at the same time contributing to the expansion of doxa beyond its earlier confines and into the realm of private life. The value attached to continuous geographical mobility within the doxa of UN organizations is a key condition that clearly shapes the ways in which mediatization unfolds in this study, giving shape to contextually specific relationships of functional, transactional, and ritual dependencies.

\section{New media practices pushing the field theoretical framework}

Bourdieu himself used a plethora of methods: statistics, observation, interviews, questionnaires, text materials, etc. (Hammerslev et. al, 2009:23). This might have the effect that all methodologies seem too narrow and that all analytical concepts and frameworks chosen are somehow lacking when seen in the light of Bourdieu's 37 books and 400 articles, covering impressive ground (Waquant, 2008:263). It is no coincidence that the authors of the articles for this special issue end their articles not with sweeping conclusions but instead with appeals for further (empirical) study in their specific research areas (Bengtsson, Waltorp), mentioning that their article are only the first "small steps" (Toft-Nielsen and Kroager), or a preliminary sketch of the field in question (Jansson).

Bourdieu did not demand that we undertake both quantitative and qualitative methodologies on a grand scale with the breadth, depth, and scope as he himself did in some of his large projects. He simply asks that the researcher make a continuous effort to triangulate methods, allowing the object of research influence the chosen methods, and continually reassess whether the applied methods were the most suitable.

Bourdieu insists that researchers always ask themselves the same questions as are asked of the data material and the informants (Hammerslev et al., 2009:13). It is important to constantly remind ourselves that the concepts we use in our analysis of the social world have a genesis and that it is exactly this history of how they came to be that is among our most effective instruments in undertaking epistemological and anthropological critiques of our own conceptual categories and forms of communication/dissemination. (Bourdieu, 1996/2009:48, 62, 82). As Couldry points out with reference to The Weight of the World (Bourdieu et al., 1999), it would have been valuable, however, with more theoretical reflection on Bourdieu's part concerning the consequences of his own distance from media and popular culture for his ability to depict convincingly contemporary experiences (of social suffering) (Couldry, 2005:22). According to Bourdieu himself, the reflexivity of the researcher/sociologist ought to take the form of an overarching critical stance to all of the organizational and cognitive structures of the sociologist, the collective unconscious of sci- 
ence, written into the academic theories of understanding problems and categorizations (Bourdieu, 1996/2009:39-44).

As mentioned above, Bourdieu's analytical concept of 'field' permits an understanding of the social cosmos as composed of a range of relatively autonomous fields. These microcosms, or force fields, are to be understood as social spaces with specific logics or demands that differ from the conditions and sets of rules of other fields (Bourdieu, 2000:99). The analytical concept of the field is thus a meso-level concept between the overarching macrolevel and the micro-level. The dual formation of habitus and field, the field structuring habitus as an internalized product of the immanent necessity of the field, is a dialectic that is constantly changing - yet at a very slow pace, making it appear to be a case of reproduction.

According to Bourdieu, all of the people who have worked with the concept habitus - from Hegel's etos to Husserl's Habitualität to Mauss' hexis - have been engaged in a theoretical project concerning how to free oneself from a subject-philosophy without relinquishing agency (Bourdieu, 1996/2009:107). Bourdieu offers us the field theoretical framework to connect between the micro-level of the agent and the macro-level of society.

As Couldry (2003) argues, there might be a piece missing though in that we are left wondering about the space between fields or about that which is not a field: In short, field theory leaves unanswered questions as to the limits, overlaps, and interrelationships of fields. When the 'structuring of habitus' occurs across partly overlapping fields, the tension between them can result in a split - or fragmented - habitus, as Bourdieu himself points out (Bourdieu, 1996/2009:112-13 in Waltorp, this issue).

Nick Couldry gives us 'media meta-capital' working across fields. In the four articles in this special issue, all authors seek ways of analytically grasping how these interplays of fields can be understood when the new media is integral to people's daily lives. Media meta-capital is one place to start, looking at the transversal effects of media capital from a macro-perspective, but we need the meso- and micro-levels studies as well. We would like this special issue to contribute to the 'first small steps' in future work, taking seriously how people's various practices surrounding new media push Bourdieu's theoretical framework and the field theoretical frame in particular in interesting directions.

Toft-Nielsen and Kroager (this issue) point out how a key component in working with practice theory and gaming is the role that 'things', technologies, and materiel structures play as important features in holding a practice together. In their context, gaming practices are directly facilitated by technology (the computer, gaming software, communication software, etc.). The material structure surrounding gaming - the physical set-up of the computers in the couples' homes - are important components for comprehending how they engage in and enact their gaming practices. Bearing in mind Bourdieu's minute observation over time in Algeria and Béarn (with close attention to the surroundings, to the material and symbolic world in which people are embedded and which they inhabit and shape as they in turn are shaped by it), Bourdieu would probably applaud careful attention 
to environment in the broadest sense, including to technological artefacts in all of their tactility and symbolic relationships with users: the computer, the smartphone, etc. This could be one place to begin future work.

We argue, finally, that the limits to Bourdieu's approach could become strengths as they allow us to mobilize the legacy of other researchers and traditions. Bourdieu's sociology is stronger due to its bridging power and ability to prompt the good questions than it is due to any claim that it offers a complete and self-sufficient sociology of media, including new media.

\section{Other articles in this issue}

This issue of MedieKultur also presents three articles in Danish. In her media-historic study, Sofie Flensburg describes the historical development of Danish press subsidies from the 1960s until the passing of the 2013 Law on Media Subsidies. By mapping the relevant changes in legislation, political discussions, and parliamentary processes, the article shows that the media-political discourse over the past 50 years has changed and that state subsidies for the private press have gone from being a controversial political issue at the start of the period to becoming a legitimate tool for media regulation. This development suggests a growing resemblance between Danish media policy and the traditions of neighbouring Scandinavian countries, where direct press subsidies and a higher degree of state regulation have prevailed since the 1970 s.

We are also happy to present two translations of classic articles in media studies, articles chosen by the readers of MedieKultur. Kim Schrøder has translated Stuart Hall's 'Encoding and Decoding in the Television Discourse' (1973). The article is accompanied by an introduction to Hall's important work on wider audience studies and reception analysis.

The other classic text selected by readers of MedieKultur as important for Nordic communication scholars is Robert Entman's 'Framing: Toward Clarification of a Fractured Paradigm', originally published in Journal of Communication in 1993. Stig Hjarvad has translated the text and introduces Entman's work in a separate article in this issue. Hjarvad highlights the importance of Entman's precise definition of the term 'framing' and the fact that Entman shows how the term can be used in wider communications and media research.

\section{References}

Baym, N.K. (1999) Tune In, Log On: Soaps, Fandom, and Online Community, Vol. 3. Sage. Benson, R. and Neveu, E. (Eds) (2004) Bourdieu and the Journalistic Field. Cambridge: Polity. Bourdieu, P. (1996) Sur la television, Paris: Liber Raisons d'agir. (Translation: On Television and Journalism. London: Pluto, 1998). 
Bourdieu, P. (1965) Un art moyen, Paris: Minuit. (Translation: Photography: A Middle-Brow Art. Cambridge: Polity, 1990).

Bourdieu, P. (1969) L'amour de l'art, Paris: Minuit. (Translation: The Love of Art: European Art Museums and Their Public. Cambridge: Polity, 1990).

Bourdieu, P. (1979) La distinction, Paris: Minuit. (Translation: Distinction. Cambridge, MA: Harvard University Press, 1984).

Bourdieu, P. (1984) Homo Academicus, Paris: Minuit. (Translation: Cambridge: Polity, 1988).

Bourdieu, P. (1984). Distinction: A Social Critique of the Judgement of Taste. Cambridge: Harvard University Press.

Bourdieu, Pierre (1975) 'L'ontologie politique de Martin Heidegger, Actes de la recherche en sciences sociales, 5/6, pp. 109-156.

Bourdieu, P. Passeron, J. And De Saint Martin, M. (1968) Rapport pedagogique et communication, Cahiers du CSE, 2, Mouton: Pris-La Haye. (Partly translated in: Academic Discourse. Cambridge: Polity, 1994).

Bourdieu, P., and Wacquant, L.J. (1996) Refleksiv sociologi: mål og midler. Hans Reitzel, Copenhagen

Bourdieu, P. (2000)Pascalian Meditations. Cambridge, Polity.

Bräuchler, B., and Postill, J. (2010) Theorising Media and Practice. New York \& Oxford: Berghahn.

Consalvo, M. (2007) Cheating: Gaining Advantage in Videogames. Cambridge, MA \& London: MIT Press.

Couldry, N. (2003) 'Media meta-capital: extending the range of Bourdieu's field theory', Theory and Society, $32(5-6), 653-77$.

Couldry, N. (2005) 'The individual point of view: learning from Bourdieu's 'The weight of the world', Cultural Studies - Critical Methodologies, 5 (3), 354-372.

Danielsson, M. (2014) Digitala distinktioner. Klass och kontinuitet i unga mäns vardag. (diss). Halmstad: Högskolan i Halmstad.

DiMaggio, P., Hargittai. E., Celeste, C., and Shafer, S. (2004) 'Digital inequality:

from unequal access to differentiated use. Pp. 355-400 In: Social Inequality, edited by Kathryn Neckerman. New York: Russell Sage Foundation.

Neveu, E. (2007) 'Pierre Bourdieu', Journalism Studies, 8 (2), 335-347

Hammerslev, O., Hansen, J.A., Larsen, K., Börjesson, M., Prieur, A., Rosenlund, L., and Esmark, K. (2009) Refleksiv sociologi i praksis. Hans Reitzels Forlag. Copenhagen

Hargittai, E. (2010) 'Digital na(t)ives? Variations in the Internet skills and uses among members of the 'Net Generation", Sociological Inquiry, 80 (1), 92-113.

Hargittai, E., and Hinnant, A. (2008) 'Digital inequality differences in young adults' use of the Internet', Communication Research, 35 (5), 602-621.

Hovden, J.F. (2008) Profane and Sacred: A Study of the Norwegian Journalistic Field, Doctoral thesis, University of Bergen.

Howard, P.E., Rainie, L., and Jones, S. (2001) 'Days and nights on the internet: the impact of a diffusing technology', American Behavioral Scientist, 45 (3), 383-404.

Meyen, M., Pfaff-Rüdinger, S., Düdenhöffer, K., and Huss, J. (2010) 'The Internet use in everyday life: a typology of Internet users', Media, Culture and Society, 32 (5), 873-882.

Møller Hartley, J. (2013) 'The online journalist between ideals and audiences: towards a (more) audiencedriven and source-detached journalism?', Journalism Practice, 7 (5), 572-587.

Møller Hartley, J. (2011) 'Routinizing breaking news categories and hierarchies in Danish online newsrooms', Making Online News, 2, 73-86.

North, S., Snyder, I, and Bulfin, S. (2008) 'Digital tastes: social class and young people's technology use', Information, Communication \& Society, 11(7), 895-911. 
Petrov, P., and von Feilitzen, C. (2005) Virtuellt rum och socialt rum: om IT i vardagslivet. Huddinge: Södertörn Academic Studies.

Reckwitz, A. (2002) 'Toward a theory of social practices', European Journal of Social Theory, 5 (2), 243-263.

Robinson, L. (2009) 'A taste for the necessary: a Bourdieuian approach to digital inequality', Information, Communication \& Society, 12 (4), 488-507.

Schatzki, T.R. (2008) Social Practices: A Wittgensteinian Approach to Human Activity and the Social, Cambridge: Cambridge University Press.

Schultz, I. (2007) 'The journalistic gut feeling', Journalism Practice, 1 (2), 190-207.

Van Dijk, J., and Hacker, K. (2003) 'The digital divide as a complex and dynamic phenomenon', The Information Society, 19, 315-326.

Van Deursen, A.J.A.M, Dijk, J. van, Peters, O.A. (2011) 'Rethinking Internet skills: the contribution of gender, age, education, Internet experience, and hours online to medium- and content-related Internet skills', Poetics, 39, 125-144.

Wacquant, L. (2008). Ch 16: Pierre Bourdieu, pp. 261-277. In Stones, R. (ed.) Key

Sociological Thinkers ( $2^{\text {nd }}$ edition), New York: Palgrave Macmillam.

Warde, A. (2005) 'Consumption and theories of practice', Journal of Consumer Culture, 5 (2), 131-153.

Wiik, J. (2010) Journalism in Transition: The Professional Identity of Swedish Journalists, PhD thesis, Gothenburg University.

Willig, I. (forthcoming) 'Field theory and media production: A bridge-building strategy"', In: Paterson, C., Lee, D., Saha, A., Zoellner, A (eds) (2016) Advancing Media Production Research: Shifting Sites, Methods and Politics, Palgrave

Willig, I. (2012) 'Newsroom ethnography in a field perspective', Journalism, 14 (3), 372-387.

Zillien, N., and Hargittai, E. (2009) 'Digital distinction: status-specific types of internet usage', Social Science Quarterly, 90 (2), 274-291.

\section{Ida Willig \\ Ph.D., Professor}

Department of Communication, Business and Information technologies

Roskilde University

idaw@ruc.dk

Karen Waltorp

Ph.D. fellow

Department of Anthropology

Aarhus University

etnkw@cas.au.dk

Jannie Møller Hartley

Ph.D., assistant professor

Department of Communication, Business and Information technologies

Roskilde University

jath@ruc.dk 